Brazilian Journal

of Chemical

\title{
MODIFICATION OF SAKO-WU-PRAUSNITZ EQUATION OF STATE FOR FLUID PHASE EQUILIBRIA IN POLYETHYLENE-ETHYLENE SYSTEMS AT HIGH PRESSURES
}

\author{
F. Gharagheizi*, M. Mehrpooya and A. Vatani \\ Department of Chemical and Polymer Engineering, Faculty of Engineering, \\ University of Tehran, Phone: (09821) 61112856, Fax: (09821)66957784 \\ P.O. Box 11365-4563, Tehran, Iran \\ Email: fghara@engmail.ut.ac.ir
}

(Received: October 11, 2005 ; Accepted: March 14, 2006)

\begin{abstract}
In order to model phase equilibria at all pressures, it is necessary to have an equation of state. We have chosen the Sako-Wu-Prausnitz cubic equation of state, which had shown some promising results. However, in order to satisfy our demands, we had to modify it slightly and fit new pure component parameters. New pure component parameters have been determined for ethylene and the $n$-alkane series, using vapor pressure data, saturated liquid volume and one-phase PVT-data. For higher n-alkanes, where vapor pressure data are poor or not available, determination of the pure component parameters was made in part by extrapolation and in part by fitting to one-phase PVT-data. Using one-fluid van der Waals mixing rules, with one adjustable interaction parameter, good correlation of binary hydrocarbon system was obtained, except for the critical region. The extension of the equation of state to polyethylene systems is covered in this work. Using the determined parameters, flash and cloud point calculations were performed, and treating the polymer as polydisperse. The results fit data well.

Keywords: Polyethylene-ethylene systems; Phase behavior.
\end{abstract}

\section{INTRODUCTION}

In the production of polyethylene, phase behavior is important for three different reasons. First, ethylene polymerization should take place in a homogeneous fluid phase since the reaction rate and subsequent product quality is easier to control if the fluid remains in a single phase (de Loos et al., 1983, 1996). Second, industrial processes to produce polyethylene are continuous, requiring the polymersolvent mixture to remain a homogeneous fluid until it reaches the separation stage. Flow problems result if the mixture separates early because the polymerrich phase has high viscosity. Third, separation of unreacted ethylene is accomplished by purposely bringing the polymer-solvent mixture into the multiphase region. The average molecular weight, molecular weight distribution and branch density all influence polymer-solvent phase behavior (Chan et al., 2000). Cloud points in polyethylene-ethylene systems have been experimentally determined for different types of polyethylene. High density polyethylene (HDPE)-ethylene systems were investigated by (de Loos 1981, Rousseaux et al., 1985, Nieszporek, 1991). Low density polyethylene (LDPE)-ethylene systems were investigated by (Swelheim et al., 1965, Steiner and Horle, 1972, Cheng and Bonner, 1977, Rätzsch et al., 1980, Spahl and Luft, 1981, 1983, 1986, Wohlfarth et al., 1981, Kobyakov et al., 1987, Nieszporek, 1991,

*To whom correspondence should be addressed 
Heukelbach and Luft, 1993,1996., de Loos et al., 1995, Muller, 1996, Horst et al., 1998, Dietzsch, 1999, Beyer et al., 2002, Buback and Latz, 2003, Trumpi et al., 2003 Becker et al., 2004, Davis et al., 2004). Systems of ethylene and different linear copolymers of polyethylene have also been examined (Heukelbach and Luft, 1993, Gregg et al., 1993, Chan et al., 2000).

Various equations of state have been proposed and modified to predict polymer-solvent phase behavior. A few of the more common are the Sanchez-Lacombe model (Sanchez and Lacombe 1976, 1978), the Kleintjens-Koningsveld Mean-Field Lattice Gas model (Kleintjens and Koningsveld, 1980), the Perturbed Hard-Sphere Chain model (Song et al., 1994a, 1994b, 1996), and the Statistical Associated Fluid Theory (SAFT) (Wertheim, 1987., Huang and Radosz, 1991).

The first attempt to apply a cubic equation of state in polymer solutions has been made by (Sako et al., 1989), introduced a three-parameter cubic equation of state, where apart from the energy $a$, and co-volume $b$, parameters, Prigogine's external degrees of freedom parameter $c$ is employed for the extension of the equation to polymers. However, the evaluation of these parameters is quite complicated for both the solvent and the polymer and thus, this approach can not retain the simplicity of a cubic equation of state.

On the other hand, (Kontogeorgis et al., 1994) proposed the use of van der Waals equation of state with a very simple method for the calculation of the attractive and repulsive parameters of the equation of state. According to this method, the parameters $a$ and $b$ of polymer are fitted to two experimental volumetric data at essentially zero pressure. The extension to polymer solution was achieved by using the classical van der Waals one fluid mixing rule, the arithmetic mean combining rule for $b_{i j}$ and the Berthelot one for $a_{i j}$ with one binary interaction parameters, $1_{\mathrm{ij}}$. In a series of papers, this approach was applied with satisfactory results to: (1) the correlation and prediction of VLE (Kontogeorgis et al., 1994, Harismiadis et al., 1994a); (2) the correlation and prediction of LLE in polymer solutions and blends (Harismiadis et al., 1994b, 1996, Saraiva et al., 1996); and (3) the correlation and prediction of Henry constants (Bithas et al., 1996).

(Orbey and Sandler, 1994), fitted the two parameters of the PRSV equation of state for the pure polymer to its volumetric data at the temperature range of interest by assuming that its vapor pressures equal to $10^{-7} \mathrm{MPa}$. In order to correlate the VLE in polymer solutions, they employed the mixing rule proposed by (Wong and Sandler, 1992) by coupling the equation of state $\mathrm{FH}$ $\mathrm{G}^{\mathrm{E}}$ model, and employing two binary interaction parameters, $\mathrm{k}_{\mathrm{ij}}$ and $\chi$ (Flory interaction parameter).

In this work we first modify the Sako-WuPrausnitz by the idea that increasing in carbon number of the n-alkanes causes a regular change in the parameters of equation of state and critical properties. Then with this procedure the parameters of this modified equation of state is estimated for heavy n-alkanes and polyethylene. Finally the phase equilibrium calculations perform.

\section{THEORY}

The Sako-Wu-Prausnitz (SWP) equation of state was developed by (Sako et al., 1989) and contains one more parameter than the better known SoaveRedlich-Kwong (SRK) equation of state. This parameter, called $\mathrm{c}$, is a measure of the number of external rotational and vibrational degrees of freedom, which makes the equation of state suitable for systems containing large molecules. The equation of state is a member of the cubic family:

$P=\frac{R T(v-b+b c)}{v(v-b)}-\frac{a(T)}{v(v+b)}$

Like in the van der Waals equation of state, the parameter $a$ accounts for the attractive forces between the molecules and parameter $\mathrm{b}$ is a measure of the molecular size. The c parameter is already mentioned, and the connection to SRK is obtained by setting $\mathrm{c}=1$, which is also the minimum physical limit for $\mathrm{c}$. The equation of state parameters, are related to the critical point, using the classical definition:

$$
\begin{aligned}
& \left(\frac{\partial \mathrm{P}}{\partial \mathrm{v}}\right)_{\mathrm{T}=\mathrm{T}_{\mathrm{c}}}=0 \\
& \left(\frac{\partial^{2} \mathrm{P}}{\partial \mathrm{v}^{2}}\right)_{\mathrm{T}=\mathrm{T}_{\mathrm{c}}}=0
\end{aligned}
$$

where subscript $C$ means at the critical point. Using the conditions (2) and (3) on the equation of state, (1), the following relations at the critical point are obtained:

$$
a_{c}=\frac{\left(1+D_{0}\right)^{3}}{18 D_{0}} \frac{R^{2} T_{c}^{2}}{P_{c}}
$$


$\mathrm{b}_{\mathrm{c}}=\frac{\mathrm{D}_{0}}{3} \frac{\mathrm{RT}_{\mathrm{c}}}{\mathrm{P}_{\mathrm{c}}}$

$c_{c}=\frac{\left(1-D_{0}\right)^{3}}{6 D_{0}^{2}}$

$\mathrm{v}_{\mathrm{c}}=\frac{1}{3} \frac{\mathrm{RT}_{\mathrm{c}}}{\mathrm{P}_{\mathrm{c}}}$

where $D_{0}$ is an adjustable parameter. The reason of why $\mathrm{D}_{0}$ suddenly pops up is purely mathematical. We have a system of 3 equations, (1), (2) and (3) which we solve with respect to four variables, $a_{c}$, $\mathrm{b}_{\mathrm{c}}, \mathrm{c}_{\mathrm{c}}$ and $\mathrm{v}_{\mathrm{c}}$. This means that three of the variables must be a function of the fourth one. Here we have introduced $\mathrm{D}_{0}$ for pure convenience, instead we could have for instance made $a_{c}$ and $c_{c}$ functions of $\mathrm{b}_{\mathrm{c}}$. The relations are the same as those obtained by (Sako et al., 1989), however Eq. (4) is simplified.

The result in Eq. (7) lead to a constant value of the critical compressibility factor:

$\mathrm{Z}_{\mathrm{c}}=\frac{\mathrm{P}_{\mathrm{c}} \mathrm{v}_{\mathrm{c}}}{\mathrm{RT}_{\mathrm{c}}}=\frac{1}{3}$

Typical experimental values for the critical compressibility factor are $0.26-0.29$ for $n$-alkanes up to octane (Poling et al., 2001) which means that deviations from experimental data are expected around the critical point. At temperatures other than the critical one:

$$
\begin{aligned}
& a(T)=a_{c} \cdot \alpha(T) \\
& b=b_{c} \\
& c=c_{c}
\end{aligned}
$$

(Sako et al., 1989) presented equation of state parameters for the n-alkane series, ethylene and polyethylene, and their results for an ethylenepolyethylene system looked promising. However, (Gregg et al., 1993) compared the SWP equation of state with the SRK equation of state and the statistical associating fluid theory (SAFT, Huang and Radosz, 1990, 1991) for a number of ethylene $+n-$ alkane systems, and it turned out that the SWP equation of state had the poorest agreement with the experimental data. This was surprising since SWP contains one more parameter than SRK, and should thereby produce equal or better results. There might be several reasons for this result, the obvious one is that there might be something wrong with the pure component parameters, and it motivated us to look further into this.

For the parameter a, (Sako et al., 1989) used one empirical temperature function for volatile fluids and for polymers they determined the temperature function from London's formula for dispersion forces. In this work we have used the Soave temperature function:

$$
\alpha(T)=\left(1+f\left(1-\sqrt{T_{r}}\right)\right)^{2}
$$

where $\mathrm{f}$ is a compound dependent parameter fitted to experimental vapor pressure and PVT-data.

\section{Evaluation of Pure Component Parameters}

Before we can use the equation of state for calculating phase equilibria for mixtures, we need to determine the pure component equation of state parameters. In our case we have a total of four parameters to be determined: $\mathrm{D}_{0}, \mathrm{~T}_{\mathrm{c}}, \mathrm{P}_{\mathrm{c}}$ and the Soave parameterf. Pure component parameters for volatile compounds are typically determined using saturated properties and relating the parameters to the critical point, which for us means that we set $T_{c}$ and $P_{c}$ to the experimental critical values and fit $D_{0}$ and $f$ to vapor pressure data. However, polymers do not have a measurable saturated pressure and decompose long before reaching the critical point, so the only data available is one phase PVT-data. For calculation of phase equilibria using an equation of state, it is always preferable that the pure component equation of state parameters, are determined from vapor pressure data. Fitting all four parameters directly to PVT-data, give a very good fit, but poor phase equilibria. Since polyethylene strictly speaking is a very large alkane, it should be possible to extrapolate some of the parameters from an alkaneseries, and fit the remaining to PVTdata.

\section{Selection of Experimental Data Points}

It is always an advantage to test experimental data which is to be used in parameter estimation in models. If we use bad data for optimization of parameters in our model, the model will likely produce poor results.

Test of vapor pressure data is typically performed graphically, and one of the most common ones is to plot $\ln (\mathrm{P})$ as a function of $1 / \mathrm{T}$. The resulting curve should then be linear for "good" data, while "bad" data should be off the linear curve. The theoretical foundation for 
this linearity was established in the $19^{\text {th }}$ century by Clapeyron and Clausius (Poling et al., 2001).

In this work first, we collected a databank of experimental vapor pressure data, and then, we performed vapor pressure graphical test which, was explained. After performing this graphical test, the best experimental vapor pressure data were selected graphically in compare of other data and, the pure PVTData collection was added to this databank (The references of this databank are available from the authors).

\section{Pure Component Parameters}

Pure component parameters are fitted to saturated vapor pressure, PVT-data and saturated liquid densities, whichever available, using a least square routine. The following objective function has been used:

$\mathrm{O}=\frac{\mathrm{w}_{\mathrm{p}}^{\text {vap }}}{\mathrm{n}_{\mathrm{p}}^{\mathrm{vap}}} \sum_{\mathrm{i}}^{\mathrm{n}_{\mathrm{p}}^{\text {vap }}}\left(1-\frac{\mathrm{P}_{\text {calc }}^{\text {vap }}}{\mathrm{P}_{\text {exp }}^{\text {vap }}}\right)^{2}+\frac{\mathrm{w}_{\mathrm{v}}^{\text {liq }}}{\mathrm{n}_{\mathrm{v}}} \sum_{\mathrm{i}}^{\mathrm{n}_{\mathrm{v}}^{\text {liq }}}\left(1-\frac{\mathrm{v}_{\text {calc }}^{\text {liq }}}{\mathrm{v}_{\text {exp }}^{\text {liq }}}\right)^{2}$

where $\mathrm{w}$ is a weighting factor, $\mathrm{P}^{\mathrm{vap}}$ is the vapor pressure, $\mathrm{v}^{\text {liq }}$ is the saturated liquid volume and $\mathrm{n}$ is the number of experimental points. Subscripts calc and expmean calculated and experimental, respectively. The following weights have been used throughout in the optimization:

$\mathrm{w}_{\mathrm{p}}^{\mathrm{vap}}=3$

$\mathrm{w}_{\mathrm{v}}^{\operatorname{liq}}=1$

Pure component parameters were determined by fitting the $\mathrm{D}_{0}$ parameter in Eqs. (4)-(6) and the temperature function parameter $f$ in Eq. (12) to the vapor pressure data and saturated liquid volumes and to the PVT-data. Values for the critical temperature and critical pressure for n-alkanes were those recommended by (Ambrose and Tsonopoulos, 1995) and for ethylene those recommended by (Tsonopoulos and Ambrose, 1996). The results are summarized in Table 1.

Figure 1 shows the fitted $\mathrm{D}_{0}$ and $\mathrm{f}$ parameters plotted against the carbon number for alkanes $\mathrm{C}_{1}-\mathrm{C}_{17}$. The scattering is expected, due to inaccuracies in experimental data used in the fitting process, but apart from this the parameters behave well. The $\mathrm{D}_{0}$ parameter is clearly a decreasing function with increasing carbon number, while the $\mathrm{f}$ parameter is an increasing function with carbon number. However, neither $\mathrm{D}_{0}$ or $\mathrm{f}$ is a linear function, making extrapolation difficult and hazardous.

Table1: Obtained results for first seventeen n-alkanes by optimization of experimental data (Gharagheizi, 2005).

\begin{tabular}{|c|c|c|c|c|c|c|c|}
\hline \multirow[b]{2}{*}{ Component } & \multirow[b]{2}{*}{ T Range } & \multirow[b]{2}{*}{$\mathbf{D}_{0}$} & \multirow[b]{2}{*}{$\mathbf{f}$} & \multirow[b]{2}{*}{$\mathbf{T}_{\mathrm{c}}$} & \multirow[b]{2}{*}{$\mathbf{P}_{\mathrm{c}}$} & \multicolumn{2}{|c|}{$\% A D$} \\
\hline & & & & & & $\mathbf{P}^{\text {vap }}$ & $\mathbf{v}^{\text {liq }}$ \\
\hline Methane & $90.69-620$ & 0.2599 & 0.4863 & 190.56 & 4.599 & 1.33 & 5.41 \\
\hline Ethane & $89.89-625$ & 0.2445 & 0.5509 & 305.32 & 4.872 & 1.77 & 3.35 \\
\hline Propane & $89.98-600$ & 0.2342 & 0.5779 & 369.83 & 4.248 & 2.59 & 5.7 \\
\hline Butane & $134.86-660$ & 0.2246 & 0.602 & 425.12 & 3.796 & 2.89 & 3.05 \\
\hline Pentane & $143.45-650$ & 0.2238 & 0.657 & 469.7 & 3.37 & 2.71 & 3.18 \\
\hline Hexane & $174.75-663.15$ & 0.2102 & 0.6469 & 507.6 & 3.025 & 2.94 & 2.2 \\
\hline Heptane & $182.56-573.15$ & 0.2063 & 0.6908 & 540.2 & 2.74 & 3.29 & 3.02 \\
\hline Octane & $216.37-623.15$ & 0.2047 & 0.7257 & 568.7 & 2.49 & 3.21 & 0.36 \\
\hline Nonane & $223.15-573.15$ & 0.2013 & 0.7677 & 594.6 & 2.29 & 2.57 & 0.84 \\
\hline Decane & $243.50-700.00$ & 0.193 & 0.7492 & 617.7 & 2.11 & 3.68 & 1.1 \\
\hline Undecane & $253.15-523.15$ & 0.1975 & 0.8468 & 639 & 1.98 & 3.41 & 2.64 \\
\hline Dodecane & $263.67-588.13$ & 0.1893 & 0.817 & 658 & 1.82 & 4.05 & 2.8 \\
\hline Tridecane & $273.65-573.15$ & 0.1827 & 0.8095 & 675 & 1.68 & 3.82 & 2.19 \\
\hline Tetradecane & $279.01-588.13$ & 0.1794 & 0.8124 & 693 & 1.57 & 3.22 & 3.3 \\
\hline Pentadecane & $293.83-576.95$ & 0.1778 & 0.8404 & 708 & 1.48 & 4.04 & 2.55 \\
\hline Hexadecane & $291.55-593.85$ & 0.1747 & 0.8455 & 723 & 1.4 & 4.78 & 2.19 \\
\hline Heptadecane & $295.15-610.15$ & 0.1731 & 0.8713 & 736 & 1.34 & 4.15 & 1.8 \\
\hline Ethylene & $79.45-450.00$ & 0.2437 & 0.5376 & 282.34 & 5.041 & 0.78 & 2.01 \\
\hline verage Deviation & $\% \mathrm{AD}=\frac{1}{100 \mathrm{n}} \sum_{\mathrm{i}}^{\mathrm{n}} \mid \frac{\mathrm{S}_{\exp }}{\mathrm{S}_{\mathrm{e}}}$ & 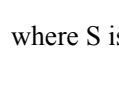 & roperty. & & & & \\
\hline
\end{tabular}




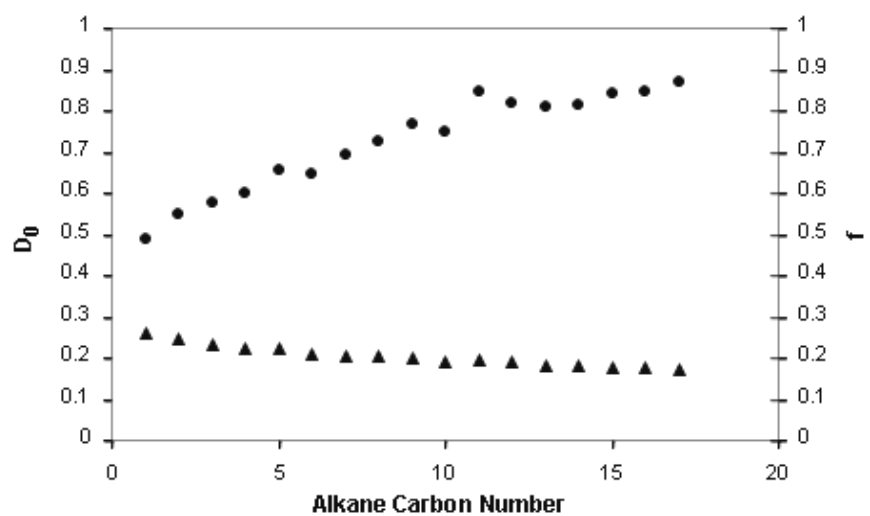

Figure 1: Change of $D_{0}$ and $f$ with carbon number for first seventeen n-alkanes

Converting $\mathrm{D}_{0}$ to $\mathrm{a}_{\mathrm{c}}, \mathrm{b}$ and $\mathrm{c}$, using Eqs. (4)- (6), gives much simpler correlations. Figure 2 to Figure 4 , shows the equation of state, parameters $a_{c}, b$ and $c$ plotted against increasing alkane carbon number. While ac shows a quadratic dependence with respect to carbon number, $\mathrm{b}$ and $c$ show a linear dependence, making them our choices for extrapolation. For alkanes higher than $C_{17}$, parameters $\mathrm{b}$ and $\mathrm{c}$ are extrapolated in the form of Eqs. (14), (15).

$$
\begin{aligned}
& \mathrm{b}=18.81 \mathrm{cn}+11.655 \\
& \mathrm{c}=0.1314 \mathrm{cn}+0.9552
\end{aligned}
$$

where $\mathrm{cn}$ is the alkane carbon number. Parameters $\mathrm{a}_{\mathrm{c}}$ and $\mathrm{f}$ are fitted to the vapor pressure data and saturated liquid volumes and to the PVT-data. The results are shown in Table 2.

The critical properties are calculated from the values of $a_{c}$, b and $c$, using Eqs. (4)- (6).



Figure 2: Equation of state parameter $\mathrm{a}_{\mathrm{c}}$ plotted as a function of increasing alkane carbon number



Figure 3: Co-volume parameter $\mathrm{b}$ plotted as a function of increasing alkane carbon number 


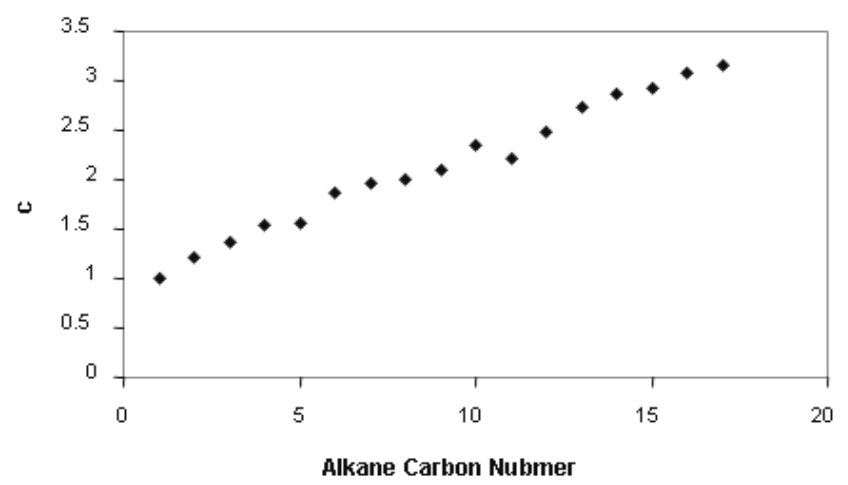

Figure 4: Parameter c plotted as a function of increasing alkane carbon number

Table 2: Obtained results for heavy n-alkanes and waxes by optimization of experimental data (Gharagheizi, 2005).

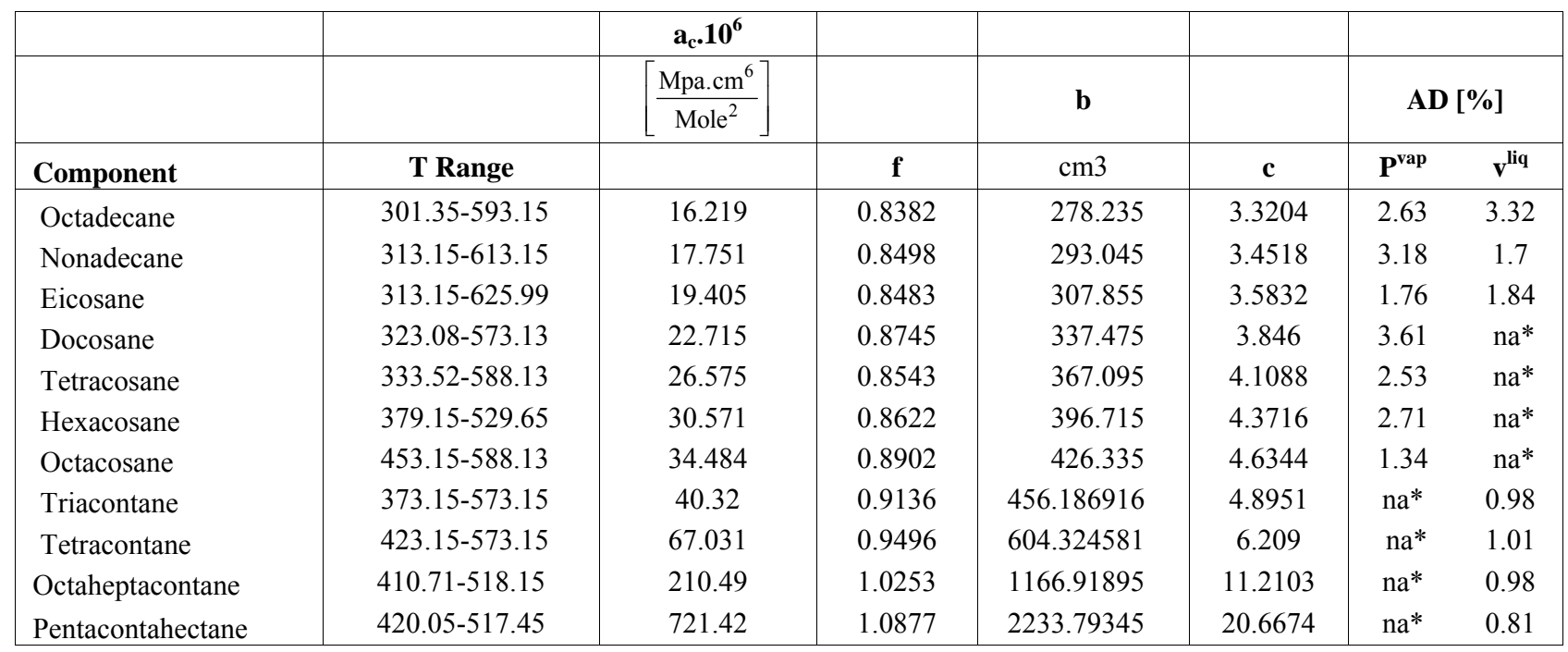

* Vapor pressures are not available.

For alkanes higher than $\mathrm{C}_{28}$ vapor pressure data are either very poor or not available at all. For these alkanes only one-phase PVT data has been used. We could try to use the same recipe as for the alkanes from $\mathrm{C}_{18}-\mathrm{C}_{28}$, however it turns out that the $\mathrm{f}$ parameter drops in value to about 0.75 for triacontane. The $f$ parameter should be an increasing function of the carbon number, due to the increase of the critical temperature. The cause of this might be the lack of vapor pressure data in the fit. This means that we need to extrapolate one more parameter for the alkanes which do not have reliable vapor pressure data. The only two left are $a_{c}$ and $f$, so let us have a close look on them both. Figure 5 shows that the attractive parameter $a_{c}$ is quadratically dependent on the alkane carbon number, as expected. However, extrapolating quadratic functions should be avoided, since possible errors also increase quadratically. $\mathrm{a}_{\mathrm{c}}=3.608 \times 10^{4} \mathrm{cn}^{2}+2.556 \times 10^{5} \mathrm{cn}-8.964 \times 10^{4} \mathrm{cn}<18$

$\mathrm{a}_{\mathrm{c}}=0.0287 \times 10^{4} \mathrm{cn}^{2}+0.544 \mathrm{cn}-5.732, \quad \mathrm{cn}>18$

Figure 6 shows that the $\mathrm{f}$ parameter might be extrapolated using a three parameter correlation. Even if we have more scattering of the f parameter than for the $a_{c}$ parameter, we choose to extrapolate the $f$ parameter. Possible errors will be much higher for the quadratic correlation, than for the correlation of $f$ and this is especially important when we plan to extrapolate all the way to polyethylene.

$$
\mathrm{f}=\frac{\mathrm{cn}}{-0.51895+1.8731 \sqrt{\mathrm{cn}}+0.76989 \mathrm{cn}}
$$

For alkanes higher than $\mathrm{C}_{28}$, parameter $\mathrm{b}, \mathrm{c}$, $a_{c}$ and $f$ are extrapolated, using Eqs. (14)- (17). 




Figure 5: Attraction parameter $\mathrm{a}_{\mathrm{c}}$ plotted as a function of alkane carbon number



Figure 6: Attraction parameter f plotted as a function of alkane carbon number

\section{Binary Mixtures}

As (Sako et al., 1989) did, we assume one-fluid mixing rules, for fluid phase equilibria for multicomponents mixtures.

$$
a_{m}=\sum_{i} \sum_{j} x_{i} x_{j} a_{i j}\left(1-k_{i j}\right)
$$

$\mathrm{b}_{\mathrm{m}}=\sum_{\mathrm{i}} \mathrm{x}_{\mathrm{i}} \mathrm{b}_{\mathrm{i}}$

$\mathrm{c}_{\mathrm{m}}=\sum_{\mathrm{i}} \mathrm{x}_{\mathrm{i}} \mathrm{c}_{\mathrm{i}}$

where subscript $m$ means mixture property and subscript $i$ means component property. $\mathrm{k}_{\mathrm{ij}}$ is an interaction parameter, which is typically fitted to phase equilibria data.
The derivation of the fugacity coefficient for component $\mathrm{i}$ by an equation of state is described in detail in (Poling et al., 2001).

Phase equilibria for binary mixtures were calculated. The principle of maximum likelihood has been used for calculation of the error. Experimental phase equilibria data consist of vapor and, or liquid composition at given pressure and temperature. We assume that the experimental temperature data are the most accurate and therefore keep $T$ constant while minimizing the following objective function for each experimental point:

$\mathrm{O}=\left(1-\frac{\mathrm{P}_{\text {calc }}}{\mathrm{P}_{\text {exp }}}\right)^{2}+\left(1-\frac{\mathrm{x}_{\text {calc }}}{\mathrm{x}_{\text {exp }}}\right)^{2}+\left(1-\frac{\mathrm{y}_{\text {calc }}}{\mathrm{y}_{\text {exp }}}\right)^{2}$

where subscript calc means calculated property and exp means experimental property. In Eq. (19) one needs to optimize with respect to one of the 
properties, while calculating the two others. For instance, optimizing $\mathrm{P}_{\text {calc }}$ leads to a PT-flash calculation of the vapor and liquid compositions. The reason for choosing the maximum likelihood method is to avoid large deviation of the calculated composition from the experimental composition in cases where the composition varies much over a small pressure range.

For optimizing the interaction parameter, $\mathrm{k}_{\mathrm{ij}}$, we use the same maximum likelihood principle. In the objective function we now need to sum over all the included data points:

$$
\begin{aligned}
& \mathrm{O}_{\mathrm{k}_{\mathrm{ij}}}=\sum_{\mathrm{i}}^{\mathrm{n}_{\exp }}\left(1-\frac{\mathrm{P}_{\text {calc }}}{\mathrm{P}_{\exp }}\right)^{2}+\sum_{\mathrm{i}}^{\mathrm{n}_{\exp }}\left(1-\frac{\mathrm{x}_{\text {calc }}}{\mathrm{x}_{\exp }}\right)^{2}+ \\
& +\sum_{\mathrm{i}}^{\mathrm{n}_{\exp }}\left(1-\frac{\mathrm{y}_{\text {calc }}}{\mathrm{y}_{\exp }}\right)^{2}
\end{aligned}
$$

Table 3 shows results of selected hydrocarbon binary systems and lists temperature and pressure ranges, optimized $\mathrm{k}_{\mathrm{ij}}$ values (if not set equal to zero), number of points used in fitting, average deviations in pressure and liquid and vapor phase composition.

\begin{tabular}{|c|c|c|c|c|c|c|}
\hline & & & & & \multicolumn{2}{|c|}{ \%AD } \\
\hline System & $\mathbf{T}[\mathrm{K}]$ & P [MPa] & $\mathbf{k}_{\mathrm{ij}}$ & No. pts & $\mathbf{P}$ & $\mathbf{x}$ \\
\hline \multicolumn{7}{|l|}{ Ethylene+ } \\
\hline Eicosane & $323-423$ & $0.49-24.40$ & 0.0211 & 88 & 1.31 & 1.29 \\
\hline Hexacosane & $348-448$ & $0.78-30.18$ & 0.0232 & 121 & 1.62 & 2.32 \\
\hline Trtracontane & 348-448 & $1-30.4$ & 0.0251 & 45 & 1.8 & 2.01 \\
\hline Tetracontane & $373-448$ & $0.9-40.56$ & 0.0293 & 90 & 1.21 & 1.64 \\
\hline
\end{tabular}

Table 3: Binary hydrocarbon systems (experimental data from de Loos et al. (1984)).

\section{Phase Equilibria in Polyethylene+Ethylene Systems}

In phase equilibria calculations, there are in general two ways to account for the molecular weight distribution of the polymer; the use of continuous thermodynamics and of pseudocomponents. Both procedures involve the use of a theoretical distribution function to represent the actual molecular weight distribution. In the continuous thermodynamics approach, the theoretical distribution function is used directly instead of mole fractions in the phase equilibria calculations, while in the pseudocomponents approach, the theoretical distribution function is divided into a number of discrete pseudocomponents, each with a given molar mass and mole fraction. Several methods on how to divide the theoretical distribution exists. (Sako et al., 1989) used the LaguerreGaussian quadrature method. This procedure is an integration method which, by the use of orthogonal polynomials, divides the function into $\mathrm{n}$ optimal parts.
In this work we used from the procedure, which used by (Sako et al., 1989), for calculation of pseudocomponents. Table 4 shows the results of this procedure for the system which presented by (Trumpi et al., 2003). In this work we used 16 pseudocomponents for polyethylene.

Pure component equation of state parameters of polyethylene pseudocomponents were determined by eqs. (14) - (17). In this work, we assumed that any polyethylene pseudocomponents, is a large $n$ - alkanes.

In this paper we select the system of polyethyleneethylene described experimentally by (Trumpi et al., 2003). The average molecular weights and the pseudocomponents in this calculation are shown in Table 4.

The results for this system containing cloud points and shadow points curves are shown in Figure 5 in comparing with experimental data.

Obtained results for $\mathrm{k}_{\mathrm{ij}}$, show the linear dependency with temperature. The $\mathrm{k}_{\mathrm{ij}}$ parameter for this system, is in the form of

$\mathrm{k}_{\mathrm{ij}}=-0.000406 \mathrm{~T}+0.137989$ 
Table 4: Characterization of Polyethylene (Trump et al. 2003) and Assumed 16 Pseudocomponents in this calculation.

\begin{tabular}{|r|c|c|c|}
\hline \multicolumn{4}{|c|}{$\begin{array}{c}\text { Molar Fraction and Molecular Weights of 16 Pseudo components } \\
\mathbf{( M}_{\mathbf{n}} \mathbf{4 8 0 0 0} \mathbf{M}_{\mathbf{w}} \mathbf{= 5 2 0 0 0 )}\end{array}$} \\
\hline Mole Fraction & Molecular Weight & Mole Fraction & Molecular Weight \\
\hline $9.393183 \mathrm{e}-010$ & 7065.215 & 0.2467892 & 51449.53 \\
\hline $5.916796 \mathrm{e}-007$ & 9805.932 & 0.1094475 & 64100.24 \\
$5.240349 \mathrm{e}-005$ & 12936.35 & 0.02615174 & 80112.38 \\
0.001399687 & 16650.28 & 0.003197568 & 100695.7 \\
0.01524479 & 21120.75 & 0.000182454 & 127731.8 \\
0.07891863 & 26547.32 & $4.123473 \mathrm{e}-006$ & 164402.6 \\
0.2114485 & 33178.8 & $2.675124 \mathrm{e}-008$ & 216886 \\
0.3071628 & 41337 & $2.204668 \mathrm{e}-011$ & 301019.7 \\
\hline
\end{tabular}

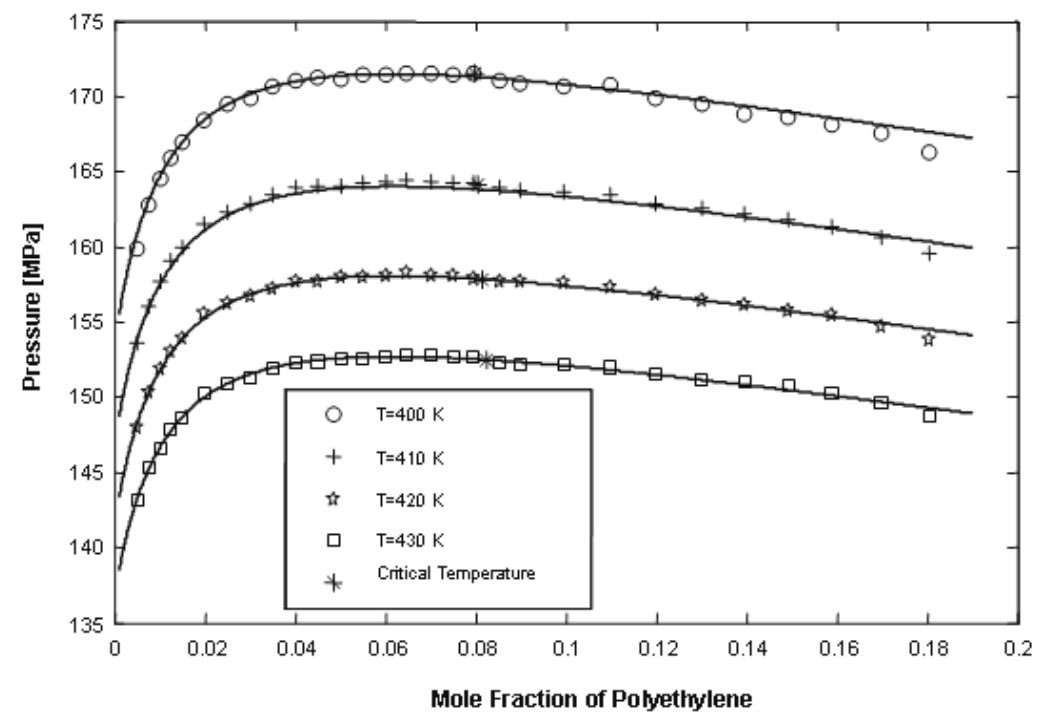

Figure 7: Isotherms of Polyethylene+Ethylene with $\mathrm{k}_{\mathrm{ij}}$ in Eq. (21). Correlation from Equation of State with 16 Pseudocomponents.

\section{CONCLUSION}

The Sako-Wu-Prausnitz equation of state was modified and extended to polyethylene. Pure component parameters for polyethylene were determined from a combination of extrapolation and fitting. The parameters $\mathrm{a}_{\mathrm{c}}, \mathrm{b}, \mathrm{c}$, and $\mathrm{f}$ were extrapolated from the results obtained by pure parameter fitting of the n-alkane series. Using the determined parameters, flash and cloud point calculations were performed, treating the polymer as polydisperse.

This modified equation of state enables us to modeling the phase behavior of all systems in the form of n-alkanes+ethylene. The same approach can be used for phase behavior of systems in the form of n-alkanes+any components. Advantage of this method is the facility of application of this equation of state for studying of phase behavior of systems.
On the other hand, the strategy of gradual change of parameters of equation of state can be used for other components homologues such siloxanes and other components that the experimental data for their systems are available in the literature for number of the repeating units. Even this strategy can be used for other physical properties in the science and engineering.

\section{NOMENCLATURE}

$\alpha \quad$ Temperature Dependent Part of a

a Attractive Parameter (MPa. $\mathrm{cm}^{6} / \mathrm{mole}^{2}$ )

b Co-Volume Parameter $\quad\left(\mathrm{cm}^{3}\right)$

c Parameter of Equation (-) of State

cn Alkane Carbon Number
$(-)$ 
$\mathrm{D}_{0} \quad$ Derived Parameter in

Sako-Wu-Prausnitz

Equation of State

f Temperature Function

Prameter

$\mathrm{k}_{\mathrm{ij}} \quad$ Interaction Parameter

$\mathrm{M}_{\mathrm{n}} \quad$ Number-average

Molecular Weight

$\mathrm{M}_{\mathrm{w}} \quad$ Mass-average

Molecular Weight

$\mathrm{O}$ Objective Function

P Pressure

$\mathrm{P}_{\mathrm{c}} \quad$ Critical Pressure

$\mathrm{P}^{\text {vap }} \quad$ Vapor Pressure

R Gas Constant

$\mathrm{T}$ Temperature

$\mathrm{T}_{\mathrm{c}} \quad$ Critical Temperature

v Molar Volume

$\mathrm{v}^{\text {liq }} \quad$ Liquid Molar Volume

\section{REFERENCE}

Ambrose, D., and Tsonopoulos, C., Vapor-Liquid Critical Properties of Elements and Compounds. 2. Normal Alkanes, J. Chem. Eng. Data, 40, 531 (1995).

Becker, F., Buback, M., Latz, H., Sadowski, G., and Tumakaka, F., Cloud Point Curves of Ethylen(meth)acrylate Copolymers in Fluid Ethylene up to High Pressures and Temperatures: Experimental Study and PC-SAFT Modeling, Fluid Phase Equilib., 215, 263 (2004).

Beyer, C., and Oellrich, L. R., Cosolvent Studies with the System Ethylene/ Poly(ethylene-coacrylic acid): Effects of Solvent, Density, Polarity, Hydrogen Bonding, and Copolymer Composition, Helv. Chim. Acta, 85, 659 (2002).

Bithas, S. G, Kalospiros, N. S., Kontogeorgis, G. M., and Tassios, D. P. , Henry Constants in Polymer Solutions with the van der Waals Equation of State, J. Polym. Eng. Sci., 36, 254 (1996).

Buback, M., and Latz, H., Cloud-Point Pressure Curves of Ethylene/ Poly[ethylene-co-((meth) acrylic acid)] Mixtures, Makromol. Chem. Phys., 204, 638 (2003).

Chan, K. C., Adidharma, H., and Radoz, M., FluidLiquid Transition of Poly(Ethylene-coOctene-1) in Supercritical Ethylene Solutions, Ind. Eng. Chem. Res., 39, 4370 (2000).

Cheng, Y. L., and Bonner, D. C., Solubility of Ethylene in Liquid, Low-Density Polyethylene to 69 Atmospheres, J. Polym. Sci.: Polym. Phys., 15, 593 (1977).
(-) Davis, P. K., Lundy, G. D., Plamara, J. E., Duda, J. L. and Danner, R. P., New Pressure-Decay Techniques to Study Gas Sorption and Diffusion in Polymers at Elevated Pressures, Ind. Eng. Chem. Res., 43, 1537 (2004).

Dietzsch, H., Hochdruck-Copolymerization von Ethen und (Meth)Acrylsäreestern, Dissertation, University of Goettingen, (1999) (in German).

de Loos, Th. W., Evenwichten Tussen Fluide Fasen In Systemen van Lineair Polyethen en Etheen, Ph.D. Thesis, Technical University of Delft, Delft, Netherland, (1981) (in Dutch).

de Loos, Th. W., Poot, W., and Diepen, G.A.M., Fluid Phase Equilibriums in System Polyethylen+Ethylene. 1. Systems of Linear Polyethylene+Ethylene at High Pressure, Macromolecules, 16, 111 (1983).

de Loos, Th. W., Poot, W. and Lichtenthaler, R. N., Fluid Phase Equilibrium in Binary Ethylene $+\mathrm{n}-$ Alkane Systems, Ber. Bunsenges. Phys. Chem., 88, 855 (1984).

de Loos, Th.W., Poot, W., and Lichtenthaler, R. N., The Influence of Branching on High Pressure Vapor-Liquid Equilibria in Systems of Ethylene and Polyethylene, J. Supercritical Fluids, 8, 282 (1995).

de Loos, Th. W., de Graaf, L. J., and de Swaan Arons, Liquid-Liquid Phase Separation in Linear Low density Polyethylene-Solvent Systems, Fluid Phase Equilib., 40, 117 (1996).

Gharagheizi, F., Application of Cubic Equations of State for Fluid Phase Equilibria in PolyethyleneEthylene Systems, Dissertation, University of Tehran, (2005) (in Persian).

Gregg, C. J., Chen, S. J., Stein, F. P., and Radoz, M., Phase Behaviour of Binary Ethylene-Propylene Copolymer Solusions in Sub- and Supercritical Ethylene and Propylene, Fluid Phase Equilib., 83, 375 (1993).

Harismiadis, V. I., Kontogeorgis, G. M., Fredenslund, Aa., and Tassios, D. P., Application of the van der Waals Equation of State to Polymers: II. Prediction, Fluid Phase Euilib. 96, 93 (1994).

Harismiadis, V. I., Kontogeorgis, G. M., Saraiva, A., Fredenslund, Aa., and Tassios, D. P., Application of the van der Waals Equation of State to Polymers III. Correlation and Prediction of Upper Critical Solution Temperatures for Polymer Solutions, Fluid Phase Equilib., 100, 63 (1994).

Harismiadis, V. I., van Bergen, A. R. D., Kontogeorgis, G. M., Fredenslund, Aa., and Tassios, D. P., Miscibility of Polymer Blends 
with Engineering Models, AIChE J., 42, 3170 (1996).

Heukelbach, D., and Luft, G., Critical Points of Mixtures of Ethylene and Polyethylene Wax under High Pressure, Fluid Phase Equilib., 146, 375 (1993) .

Heukelbach, D., Einfluss der Polydispersität von Polyetylene auf das Phasenverhalten mit Überkritischem, Dissertation, Technical University of Darmstadt, Darmstadt (1996) (in German).

Horst, R., Wolf, B. A., Kinzl, M., Luft, G., and Folie, B., Shear Influences on the Solubility of LDPE in Ethene, J. Supercritical Fluids, 14, 49 (1998).

Huang, S. H., and Radosz, M., Equation of State for Small, Large Polydisperse and Associating Molecules: Extension to Fluid Mixtures, Ind. Eng. Chem. Res., 30, 1994 (1991).

Koak, N., and Heidemann, R. A., Phase Boundary Calculation for Solutions of a Polydisperse Polymer, AIChE J., 47, 1219 (2001).

Kleintjens, L. A., and Koningsveld, R., LiquidLiquid Phase Separation in Multicomponent Polymer Systems, XIX. Mean Field Lattice Gas Treatment of the System n-Alkane/ LinearPolyethylene, Colloid Polym. Sci., 258, 711 (1980).

Kobyakov, V. M., Kogan, V. B., and Zernov, V. S., Metod otsenki dannykh o parozhidkostnom ravnovesii pri vysokikh davleniyakh, Zh. Prikl. Khim, 60, 81 (1987) (in Russian).

Kontogeorgis, G. M, Harismiadis, V. I., Fredenslund, Aa., and Tassios, D. P., Application of the van der Waals Equation of State to Polymers: I. Correlation, Fluid Phase Equilib., 96, 65 (1994).

Müller, C., Untersuchungen Zum Phasenverhalten von Quasibinären Gemischen aus Ethylen und Ethylen-Copolymeren, Dissertation, University of Karlsruhe (1996) (in German).

Nieszporek, B., Untersuchungen Zum Phasenverhalten Quasibinärer und Quasibinärer unter Druck, Dissertation, Technical University of Darmstadt, Darmstadt (1991) (in German).

Orbey, N., and Sandler, S. I., Vapor-Liquid Equilibrium of Polymer Solutions Using a Cubic Equation of State, AIChE J., 40, 1203 (1994).

Poling, B. E., Prausnitz, J. M., and O'Connell, J. P., The Properties of Gases and Liquids, McGrawHill, New York (2001).

Rätzsch, M., Findeisen, R., and Sernov, V. S., Untersuchungen Zum Phasenverhalten von Monomer-Polymer-Systemen unter Hohem Druck, Z. Phys. Chemie, Leipzig, 261, 995 (1980) (in German).
Rousseaux, P., Richon, D., and Renon, H., EthylenePolyethylene Mixtures, Saturated Liquid Densities and Bouble Pressure up to $26.1 \mathrm{MPa}$ and 493.1 K, J. Polym. Sci.: Polym. Chem., 23, 1771 (1985).

Sako, T., Wu, A. H., and Prausnitz, J. M., A Cubic Equation of State for High-Pressure Phase Equilibria of Mixtures Containing Polymers and Volatile Fluids, J. Appl. Polym. Sci., 38, 1839 (1989).

Sanchez, I. C., and Lacombe, R. H., An Elementary Molecular Theory of Classical Fluids: Pure Fluids, J. Phys. Chem., 80, 2352 (1976).

Sanchez, I. C. and Lacombe, R. H., Statistical Thermodynamics of Polymer Solutions, Macromolecules, 11, 1145, (1978).

Saraiva, A., Kontogeorgis, G. M., Harismiadis, V. I., Fredenslund, Aa., and Tassios, D.P., Application of the van der Waals Equation of State to Polymers IV. Correlation and Prediction of Lower Critical Solution Temperatures for Polymer Solutions, Fluid Phase Equilib., 115, 73 (1996).

Soave, G., Equilibrium Constants from a Modified Redlich-Kwong Equation of State, Chem. Eng. Sci., 27, 1197 (1972).

Song, Y., Lambert, S. M., and Prausnitz, J. M., A Perturbed Hardsphere Equation of State for Normal Fluids and Polymers, Ind. Eng. Chem. Res. 33, 1047 (1994).

Song, Y., Lambert, S. M. and Prausnitz, J. M., Liquid-Liquid Phase Diagrams for Binary Polymer Solutions from A Perturbed HardSphere-Chain Equation of Estate, Chem. Eng. Sci. 49, 2765 (1994).

Song, Y., Hino, T., Lambert, S. M., and Prausnitz, J. M., Liquid-Liquid Equilibria for Polymer Solutions and Blends, Including Copolymers, Fluid Phase Equilib., 117, 69 (1994).

Spahl, R., and Luft, G., Entmischungsverhalten von Ethylen und Niedermolekularem Polyethylen, Ber. Bunsenges. Phys. Chem., 85, 379 (1981) (in German).

Spahl, R., and Luft, G., Fraktionierungserscheinubgen Bei der Entnischung von Ethylen-PolyethylenGemischen, Angew. Makromol. Chemie, 115, 87 (1983) (in German).

Spahl, R., and Luft, G., Einfluss von Molmasse und Molekülverzwweigungen auf das Entmiachungsverhalten von Ethylen/PolyethylenSystemen unter Hochdruck, Ber. Bunsenges. Phys. Chem., 86, 621 (1986) (in German).

Steiner, R., and Horle, D., Phaseenverhalten von Ethylene/Polyethylene-Gemischen unter Hohem 
Druck, Chemie-Ing. Techn., 44, 1010 (1972) (in German).

Swelheim, T., de Swaan Arons, J., and Diepen, G. A. M., Fluid Phase Equilibria in the System Polyethylene-Ethylene, Recueil, 84, 261 (1965).

Trumpi, H., de Loos, Th. W., Krenz, R. A., and Heidemann, R. A., High Pressure Phase Equilibria in the System Linear Low Density Polyethylene+Ethylene: Experimental Results and Modelling, J. Supercritical Fluids, 27, 205 (2003).

Tsonopoulos, C., and Ambrose, D., Vapor-Liquid Critical Properties of Elements and Compounds. 2. Normal Alkanes, J. Chem. Eng. Data, 40, 531 (1995).
Tsonopoulos, C., and Ambrose, D., Vapor-Liquid Critical Properties of Elements and Compounds. 6. Unsaturated Aliphatic Hydrocarbons, J. Chem. Eng. Data, 41, 645 (1996).

Wertheim, M. S., Thermodynamic Perturbation Theory of Polymerization, J. Chem. Phys., 87, 7323 (1987).

Wohlfarth, C., Rätzsch, M. T., and Weber, K., Berechnungen Zum Hochdruckphasengleichgewicht in Mischungen aus Ethylen und Polyethylen II, Acta Polym., 32, 740 (1981) (in German).

Wong, D. S. H., and Sandler, S. I., Theoretically Correct New Mixing Rule for Cubic Equations of State, AIChE J., 38, 671 (1992). 
This article has received corrections in agreement with the ERRATUM published in Volume 23 Number 4. 